\title{
RAIOS-X: FASCINAÇÃO, MEDO E CIÊNCIA
}

Rodrigo da Silva Lima e Júlio Carlos Afonso*

Departamento de Química Analítica, Instituto de Química, Universidade Federal do Rio de Janeiro, Av. Athos da Silveira Ramos, 149, 21941-909 Rio de Janeiro - RJ, Brasil

Luiz Cláudio Ferreira Pimentel

Instituto de Radioproteção e Dosimetria, Comissão Nacional de Energia Nuclear, Av. Salvador Allende, s/n, $22780-160$ Rio de Janeiro - RJ, Brasil

Recebido em 25/10/07; aceito em 20/6/08; publicado na web em 10/12/08

\begin{abstract}
X-RAYS: FASCINATION, FEAR AND SCIENCE. This work presents the discovery and the use of x-rays at the end of the XIXth and the beginning of the XXth century. X-rays greatly impacted science and everyday life. Their existence broke the idea that knowledge had reached a limiting step. In general, people regarded x-rays as a marvel of science, but reactions against their use were also found. Several applications were proposed, especially in medicine. However, little or no attention was paid to security measures, leading to health damages and even death. The development of the radiological protection took into account the accidents with the x-rays.
\end{abstract}

Keywords: x-rays; radiography; radiation.

\section{A DESCOBERTA DOS RAIOS-X}

Em 8/11/1895, Wilhelm Conrad Roentgen (1845-1923), procurando detectar a radiação eletromagnética de alta freqüência prevista por Heinrich Hertz (1857-1894), repetiu o experimento de Joseph John Thompson (1856-1940) em seu laboratório, na Universidade de Wurzburgo, Alemanha. ${ }^{1,2}$ Com um tubo de Crookes, "Roentgen tentou observar um estranho fenômeno descrito pelo físico Philipp Lenard [1862-1947]: os raios catódicos que escapavam do tubo termiônico iluminavam uma superfície a uma certa distância do tubo, que tinha recebido uma camada de material fosforecente". ${ }^{3}$ Após embalar o tubo com uma caixa de papelão preto, ligar o instrumento e apagar as luzes de seu laboratório, observou algo notável: uma placa no fundo da sala, que continha tetracioanoplatinato(II) de bário $\left(\mathrm{Ba}\left[\mathrm{Pt}(\mathrm{CN})_{4}\right]\right.$, um material fosforescente) em uma das faces, se iluminou, e isso acontecia mesmo se a superfície da placa estivesse virada ao contrário. ${ }^{2,4}$

Roentgen assim descreve algumas propriedades da radiação que acabara de descobrir: "Ela produzia luminescência em certos materiais fluorescentes, sensibilizava chapas fotográficas, mas em si era invisivel ao olho humano, não parecia sofrer refração, nem reflexão, nem polarização. Não se tratava de luz (por ser invisível e atravessar grandes espessuras de madeira ou papel), não era igual aos raios catódicos (não sofria desvio com ímãs e tinha poder de penetração muito superior), nem aos raios ultravioleta ou infravermelho (pelo seu poder de penetração)"., ", Com base nessas observações, Roentgen chegou à conclusão de que se tratava de um novo tipo de raio invisível, com poder de penetração ainda desconhecido, capaz de atravessar materiais opacos à luz e a outras radiações conhecidas (raios catódicos, raios ultravioleta e infravermelho)., ${ }^{2,7}$

Esse fenômeno aguçou tanto o interesse de Roentgen que continuou estudando intensamente suas propriedades e características. Expondo diversos materiais de densidades diferentes a fim de observar seu poder de penetração, e com auxílio de um detetor fluorescente, fez uma importante observação: segurando um disco de chumbo com a mão na intenção de verificar o poder de penetração dos raios naquele

*e-mail: julio@iq.ufrj.br metal, viu que, além da sombra do disco, apareceu a sombra dos ossos da sua mão. ${ }^{2}$ Estava assim descoberta a radiografia.

Para publicar suas observações, Roentgen passou a empregar placas fotográficas ${ }^{2}$ na revelação das imagens que conseguia com a exposição de objetos à radiação, em substituição ao detetor fluorescente. Essas placas fotográficas possuíam nitrato de prata. Sob ação da radiação, o íon $\mathrm{Ag}^{+}$se reduzia $\mathrm{Ag}^{\circ}$, clareando a parte exposta que foi atravessada e sofreu ação direta da radiação, e mantendo escura a parte mais densa do corpo em estudo, a qual sofreu menos ação da radiação. A revelação da placa produzia um tipo de registro permanente, capaz de comprovar seus estudos. Foi utilizando esta técnica que, em 22/12/1895, produziu uma das mais famosas fotografias que caracterizam bem aquela descoberta: a imagem dos ossos da mão de sua mulher, Anna Bertha Roentgen (1839-1919), com seu anel de casamento, que é considerada a primeira radiografia da história. ${ }^{2,7,8}$

A 28/12/1895, menos de 2 meses depois de sua primeira observação, Roentgen fez o primeiro comunicado sobre os dados de suas observações sobre os raios-X. ${ }^{5}$ Esse foi o nome dado a eles porque não se tinha idéia da sua origem (mais tarde eles foram rebatizados como raios Roentgen).

Por esse trabalho, Roentgen recebeu o $1^{\circ}$ Prêmio Nobel de Física, em 1901. No entanto, enfrentou a desconfiança de cientistas. Muitos pesquisadores famosos como Herbert Jackson (1863-1936), Johann Hittorf (1824-1914), Eugen Goldstein (1850-1930), Willian Crookes (1832-1919) e, particularmente, Philipp Lenard, teriam detectado fenômenos de fluorescência próximos a tubos de descarga. ${ }^{7}$ Contudo, ou interpretaram erroneamente aquele fato, ou não se detiveram na análise do fenômeno. Ao contrário, Roentgen dedicou-se intensamente ao estudo do mesmo. Ele também optou por responder aos críticos com atitudes nobres: doou o dinheiro que ganhou com o Prêmio Nobel à Universidade de Wurzburgo. "Eu considero que o trabalho de uma universidade deve beneficiar a todos, sem idéia de lucro", afirmou na época. ${ }^{9}$

\section{A INTERPRETAÇÃO DA RADIAÇÃO X}

A primeira grande questão referia-se à natureza da nova radiação. Era comum a confusão que se fazia entre raios-x e os raios catódicos. ${ }^{10}$ 
Não apenas os jornais usavam indistintamente esses dois termos, mas também alguns físicos. ${ }^{10}$ É importante salientar que a caracterização da natureza dos raios catódicos (feixe de partículas de carga elétrica negativa - os elétrons) foi fruto do trabalho de Joseph John Thomson, cerca de 2 anos após a descoberta dos raios-x por Roentgen. Em busca de uma explicação para tal fenômeno, diversas hipóteses foram levantadas ${ }^{7,11}$ : os raios-x eram ondas eletromagnéticas transversais de pequeno comprimento de onda, semelhantes à radiação ultravioleta; esses raios seriam ondas eletromagnéticas longitudinais (hipótese levantada pelo próprio Roentgen); a radiação x corresponderia a pulsos não periódicos de radiação eletromagnética; os raios-x eram de natureza corpuscular, formados por raios catódicos modificados (neutros). Depois de extensivos experimentos, a polêmica foi decidida favoravelmente à primeira hipótese. ${ }^{1,12}$

Quando, em 1905, Albert Einstein (1879-1955) propôs a idéia do fóton de energia, um conceito que admitia um caráter corpuscular para a luz, foi possível calcular o comprimento de onda associado aos raios-X, mas evidências experimentais concretas de seu caráter corpuscular só surgiriam na década seguinte: ${ }^{2}$ em 1912, Max von Laue (1879-1960) e seus estudantes Walter Friedrich (1883-1968) e Paul Knipping (18831935) descobriram a difração dos raios-x em cristais de sulfeto de zinco $(\mathrm{ZnS})$, uma experiência definitiva para o estabelecimento do caráter ondulatório dessa radiação. ${ }^{13}$ A dualidade onda-partícula da radiação eletromagnética (e de toda a matéria) somente foi resolvida com os trabalhos de Louis Victor P. R. de Broglie (1892-1987), em 1923.14

Outra dificuldade se referia ao modo como eram produzidos os raios-x. Sabia-se que quando uma descarga elétrica ocorria no tubo de Crookes, a parede do tubo defronte ao catodo ficava luminescente. Era dali que os raios-x eram produzidos. ${ }^{7}$ Nos primeiros meses de 1896, dentre os diversos trabalhos apresentados à Academia Francesa de Ciências, havia os que descreviam outros modos de produzir os raios-X..$^{15,16}$ Por exemplo, em 3/2, Moreau ${ }^{15}$ descreveu que eles eram gerados por meio de descarga de alta voltagem de uma bobina de indução, sem o uso de tubo de vácuo (e sem a intervenção dos raios catódicos); 21 dias depois, Piltchikof relatou que colocou uma substância fluorescente dentro do tubo de Crookes, no ponto onde os raios catódicos atingiam o vidro. Os raios-x emitidos eram mais intensos, reduzindo o tempo da radiografia de alguns minutos para $30 \mathrm{~s}^{17}$

Hoje, sabe-se que os raios-x são radiações eletromagnéticas de alta energia oriundas de transições eletrônicas de níveis e subníveis mais internos no átomo, podendo ser de dois tipos: por interações nucleares ou por freamento. Entendem-se como interações nucleares a captura ou a expulsão de elétrons da camada interna pelo núcleo instável (radionuclídeo), gerando um orbital vazio que é preenchido por um elétron de camada mais externa, sendo a diferença de energia dos orbitais emitida na forma de radiação x. Os raios-x de freamento são produzidos por interações de partículas carregadas (preferencialmente elétrons) com o campo elétrico de núcleos ou com a eletrosfera de átomos de elevado número atômico. Com o choque, há redução da energia cinética e mudança de direção; esta diferença de energia é emitida na forma de raios-x. Este modo de formação é utilizado para gerar raios-x para uso médico e industrial, pois depende exclusivamente da energia das partículas incidentes, gerando desde centenas de $\mathrm{KeV}$ até centenas de $\mathrm{MeV}$, conforme a aplicação desejada (Tabela 1). ${ }^{18}$

Tabela 1. Diferença de potencial para geração de raios-x segundo a aplicação dos mesmos

\begin{tabular}{lc}
\hline Aplicação & Tensão \\
\hline Radiologia oral & $50-90 \mathrm{kV}$ \\
Radiodiagnóstico & $100-150 \mathrm{kV}$ \\
Radiografia industrial & $150-500 \mathrm{kV}$ \\
\hline
\end{tabular}

Os raios-x possuem alta energia e são radiações ionizantes, como as emissões nucleares (radiação gama). ${ }^{14}$ Os raios-x não emitidos por desequilíbrio nuclear são considerados fontes artificiais de radiação. ${ }^{14,18} \mathrm{O}$ comprimento de onda da luz visível é mil vezes maior que o dos raios-x. ${ }^{14}$

\section{A REPERCUSSÃO DOS RAIOS-X NA IMPRENSA E NO MUNDO CIENTÍFICO}

"O ruído de alarmes de guerra não deve desviar nossa atenção do maravilhoso triunfo da ciência que foi noticiado em Viena. Foi anunciado que o Professor Roentgen, da Universidade de Wurzburgo, descobriu uma luz que, para as finalidades de fotografia, pode penetrar através de madeira, carne e a maioria das substâncias orgânicas. o professor fotografou com sucesso objetos maciços de metal que se encontravam dentro de uma caixa de madeira; também a mão de um homem, que mostrava apenas os ossos, a carne sendo invisível". Este texto reproduz parte de uma notícia publicada pelo jornal Daily Chronicle de Londres, em 6/1/1896. A matéria havia sido telegrafada pelo seu correspondente em Viena onde, no dia anterior, o Wiener Presse, jornal daquela cidade, havia publicado na sua primeira página um artigo sobre a descoberta dos raios-x, no final do ano anterior. Isso dá uma clara idéia da admiração com que a possibilidade de fotografias através de corpos opacos, viabilizada por essa descoberta, foi recebida pela imprensa. A cobertura jornalística dada aos raios-X não tem comparação com a que foi dada a outras notícias e descobertas científicas do século XIX. ${ }^{19} \mathrm{~A}$ notícia chegou à Nova Iorque em 8/1/1896. ${ }^{19}$ Essas primeiras publicações sempre eram acompanhadas de radiografias de ossos e outros objetos ocultos. Por isso, o impacto dessas manchetes de primeira página foi enorme..$^{20,21}$

Cerca de 40 dias depois da primeira notícia em jornal, foram publicadas em fevereiro de 1896, em dois jornais de grande circulação no Rio de Janeiro (então capital federal), duas matérias sobre os raios-x. ${ }^{22,23}$ Nessas publicações foram relatadas informações ainda muito imprecisas no que diz respeito ao fenômeno em si e algumas aplicações que comprovavam sua existência e demonstravam que muito se esperava dele. Pairava no ar um sentimento de euforia sobre uma luz misteriosa, mas que representava esperança renovada em termos médicos.

Sua divulgação também logo alcançou grande impacto na comunidade científica. Durante o ano de 1896, mais de 1.000 artigos e 49 livros sobre os raios-x foram publicados.$^{8,12,24} \mathrm{O}$ primeiro artigo publicado por um pesquisador não europeu foi nos Estados Unidos, na revista Science. ${ }^{25}$ Pesquisadores em todo o mundo passaram a repetir as experiências de Roentgen, não apenas na tentativa de descobrir novas aplicações, como também com o objetivo de compreender o fenômeno. ${ }^{2,9,18}$ Henrique Morize (1860-1930), professor catedrático de Física Experimental da Escola Politécnica do Rio de Janeiro, e diretor do Observatório Nacional, foi o primeiro a descrever as aplicações dos raios-x para fins de radiografia no Brasil, em 1896. ${ }^{26}$ Ainda naquele ano foram realizadas as primeiras radiografias no país, tanto para demonstração como para uso médico, ${ }^{27}$ bem como foram apresentadas "teses" sobre a aplicação dos raios-x na medicina. ${ }^{28}$ "As primeiras radiographias executadas no Brasil foram no Laboratório de Physica da Escola Polytechnica do Rio de Janeiro (...). Utilizaram para isso um simples tubo de Crookes, do modelo chamado de "cruz", e destinado a demonstrar a marcha rectlínea dos raios catódicos, e uma pequena bobina de Gaiffe. Obtiveram assim radiographias muito incorrectas, de uma chave e outros objectos metallicos encerrados numa caixa, e de uma mão, que exigiu uma hora de exposição. Os originais dessas radiographias trazem a data de 20 de março de 1896". ${ }^{26}$

"O Dr. Henrique Morize mandou vir mais tarde da Inglaterra dois 
pequenos tubos "focus", então recentemente inventados, e um pouco de fluoreto duplo de uranila e amônio, com o qual confeccionou um pequeno anteparo fluorescente (...) e depois executou as primeiras radioscopias realmente nítidas. Essas experiências realizadas num laboratório do Observatório Astronômico foram muito concorridas (...) ". ${ }^{26}$ A Escola Politécnica da UFRJ conserva várias dessas radiografias (Figuras 1 a 4). Algumas delas trazem indicação da data "6 de novembro de 1896".

Para Roentgen, afora o reconhecimento de alguns cientistas, e o ciúme e o ceticismo de outros, a obsessão de exibir radiografias, extremamente explorada pela imprensa, acabou por deturpar o real valor da sua descoberta, impedindo-o inclusive de prosseguir com suas pesquisas. ${ }^{7,19}$ Ele optou por continuar sua carreira acadêmica. ${ }^{19}$

O final do século XIX era marcado por uma onda de otimismo e confiança no progresso da humanidade alicerçada no desenvolvimento científico e tecnológico. Pensava-se que a Física tinha atingido seu limite, faltando apenas um "refinamento de medidas". ${ }^{19,20}$ A radiação x era um fenômeno não previsto pelas teorias da época. ${ }^{7}$ Isto significava o rompimento da idéia então estabelecida de um limite do estágio do conhecimento. A ela logo se sucederam a determinação da natureza dos raios catódicos e a radioatividade. Esses fenômenos não explicáveis e previstos pelas teorias vigentes exigiam que o conhecimento

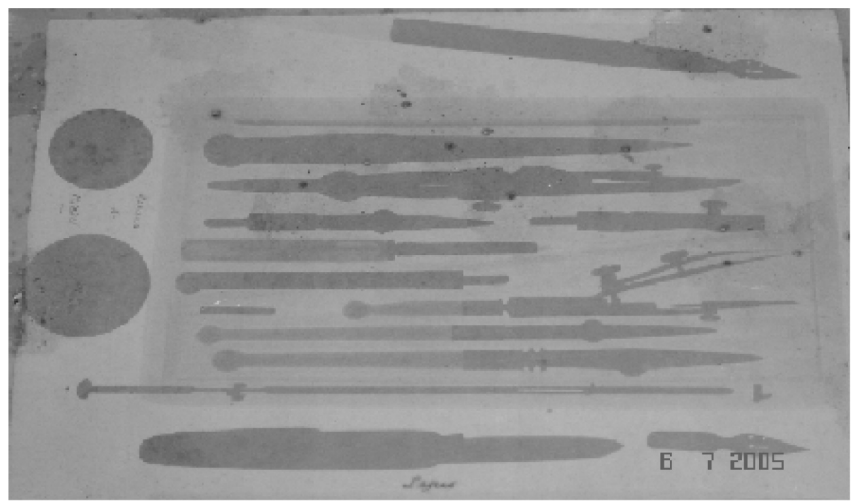

Figura 1. Radiografia de vários objetos através de uma caixa de madeira feita pelo Prof. H. Morize. Faixa $12 \mathrm{~cm}$; distância $25 \mathrm{~cm}$; exposição de 2 min; tubo "Focus". Datado de 6/11/1896. Acervo do Museu da Escola Politécnica da UFRJ

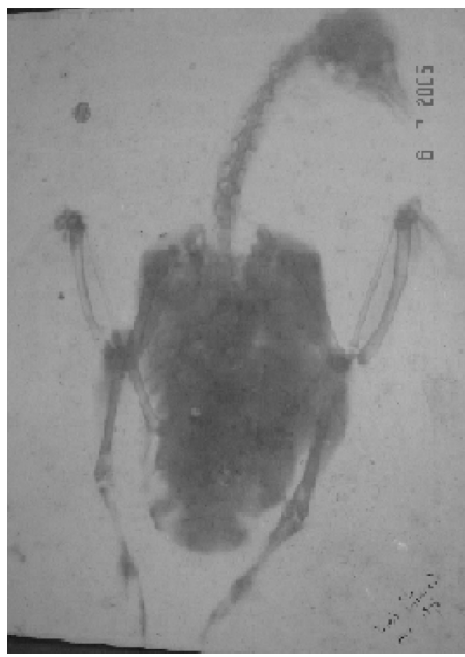

Figura 2. Radiografia de uma ave feita em maio de 1896 pelo Prof. H. Morize. Acervo do Museu da Escola Politécnica da UFRJ

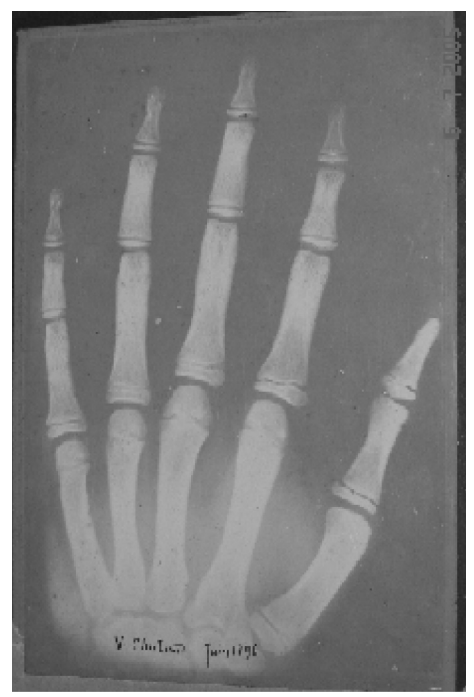

Figura 3. Radiografia de mão esquerda feita em 6/11/1896 pelo Prof. H. Morize. Acervo do Museu da Escola Politécnica da UFRJ

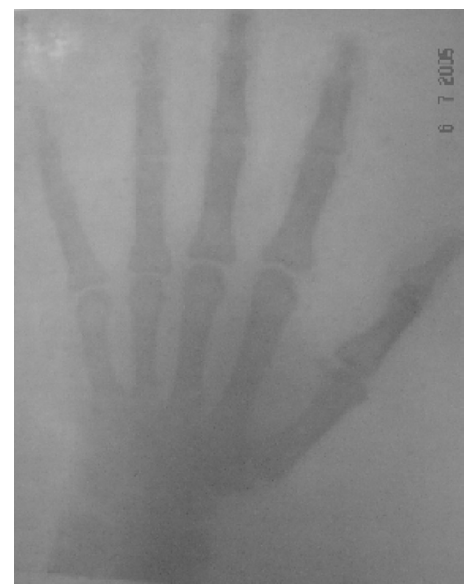

Figura 4. Radiografia de mão direita feita em 6/11/1896 pelo Prof. H. Morize. Acervo do Museu da Escola Politécnica da UFRJ

humano evoluísse para a compreensão dos mesmos. Em particular, o conhecimento sobre a estrutura da matéria ainda era precário, apenas o estado gasoso tinha uma teoria relativamente bem desenvolvida. ${ }^{29}$ Isso estimulou inúmeras pesquisas, culminando com o que pode ser considerada a maior contribuição da ciência no início do século XX: o desvendamento da estrutura atômica. ${ }^{29}$

\section{A REPERCUSSÃO DOS RAIOS-X NAS PESSOAS EM GERAL}

Além do enorme impacto na comunidade científica, é interessante avaliar o interesse despertado na comunidade leiga, que muito contribuiu para a criação de um folclore em torno do fenômeno. Em 1896, Thomas Alva Edison (1847-1931) inventou um instrumento que permitia ver a radiografia numa tela fluorescente, sem necessidade de revelar filmes, o fluoroscópio. ${ }^{2,3}$ Isso ajudou sobremodo a difusão dos raios-x no mundo leigo, pois a aparelhagem geradora era relativamente de fácil acesso. ${ }^{3}$ Além das versões usadas em hospitais e lojas, havia também um modelo caseiro (o "Vitascope", na verdade, um brinquedo!), e propaganda do tipo "faça você mesmo seu raios$\mathrm{x}$ " ${ }^{30}$ Lojas de departamento ofereciam exibições com raios-x como uma maneira de atrair clientes. ${ }^{19}$ 
Sessões de raios-x intercalavam-se com a exibição de curtasmetragens, ${ }^{19}$ aproveitando outra invenção marcante do final do século XIX: o cinema. O fascínio de ver estruturas ocultas e partes do corpo humano (e de animais) virou moda na sociedade daquela época. Isso floresceu uma indústria que vendia fluoroscópios empregados nas ruas e operados manualmente (em 1902, surgiu na Inglaterra uma versão que funcionava com moedas), ${ }^{2}$ para que as pessoas que quisessem e pelo tempo que desejassem pudessem ver as maravilhas da radiografia, ou então se pagava ao demonstrador que ficava horas expondo-se à radiação para deleite dos expectadores. ${ }^{31}$ Em revistas da época, ${ }^{32}$ radiografias eram usadas para compor capas, exercitando a imaginação popular sobre o que aquela radiação podia revelar de oculto.

Muitas notícias pitorescas foram publicadas em jornais, tanto de circulação nacional como local. ${ }^{33}$ A título de ilustração, ${ }^{10}$ no dia $11 / 2 / 1896$, saiu uma nota dando conta de uma invenção que permitia ao olho humano "ver os raios-x". No dia 13/2, um jornal informava que Roentgen havia iluminado seu cérebro e visto sua pulsação. No dia seguinte, uma matéria relatava a opinião, defendida por alguns cientistas, de que a descoberta de Roentgen poderia estabelecer novas teorias sobre a criação do mundo. Outra matéria alertava para a vulnerabilidade a que todos estavam sujeitos depois da descoberta dos raios-x: qualquer um de posse de um tubo de vácuo, dizia o jornal, podia ter uma visão completa do interior de uma residência. Outras manchetes sugeriam aplicações fantásticas, como a de ressuscitar pessoas eletrocutadas.

A beleza foi um grande mercado para os raios-x. No fim do século $\mathrm{XIX},{ }^{34}$ já se sabia que uma exposição prolongada aos raios-x levava à queda de cabelo. Isso bastou para que os salões de beleza dispusessem de um aparelho de raios-x para que as mulheres removessem (sem dor) os cabelos indesejáveis na face e no couro cabeludo, e até clareassem a pele, como era costume na moda daquele tempo. ${ }^{30,35}$ A notícia sensacionalista de que os raios-x podiam converter um homem negro em branco causou furor entre as mulheres e mesmo homens que desejavam uma cútis esbranquiçada: "Extra: Raios- $x$ Convertem Homem Negro em Branco - Negros Etíopes Transformados em Brancos Caucasianos!". ${ }^{36} \mathrm{E}$ ainda havia relatos de tratamentos faciais para eliminação das rugas, acnes, cravos, etc... sendo que "testemunhos" de resultados mirabolantes buscavam seduzir novos consumidores, como neste exemplo de um anúncio: "Os raios desse tal de Sr. Roentgen são realmente prodigiosos. Em alguns casos o tratamento com 'banhos de luzes' mudou completamente a aparência de mulheres entre 40 e 50 anos de idade. As rugas desapareceram, a fisionomia jovial foi restaurada e os pacientes recuperaram ofrescor da vida quando eram moças!". ${ }^{37}$

O caráter sensacionalista que o assunto estava despertando motivou a publicação do seguinte editorial: "Sempre que algo extraordinário é descoberto, uma multidão de escritores apodera-se do tema $e$, não conhecendo os princípios científicos envolvidos, mas levados pelas tendências sensacionalistas, fazem conjecturas que não apenas ultrapassam o entendimento que se tem do fenômeno, como também em muitos casos transcendem os limites das possibilidades. Este tem sido o destino dos raios- $x$ de Roentgen". ${ }^{38}$

Um dos exemplos mais duradouros de como os raios-x estiveram presentes no cotidiano refere-se ao fluoroscópio empregado nas grandes sapatarias, especialmente a partir de 1920: o cliente podia experimentar seus sapatos vendo a imagem dos pés e o contorno do calçado na tela fluorescente (Figura 5). Alguns modelos tinham mais de um visor e chapas para a impressão da imagem vista na tela. $\mathrm{O}$ aparelho ficava geralmente no centro da loja, ${ }^{39}$ e sua carcaça era feita de aço e madeira. Na Inglaterra surgiu um dispositivo parecido, mas menor: o "pedoscópio", patenteado em 1926, embora pareça que já era usado havia pelo menos $5 \operatorname{anos}^{40}$ (nos Estados Unidos, a patente do fluoroscópio saiu em $1927^{41}$ ). Até o início da década de 50 essa prática era muito comum, e somente nos Estados Unidos havia mais de 10.000 aparelhos em uso, 3.000 na Inglaterra e 1.000 no Canadá, a maioria dos quais desregulado e com vazamento de radiação para o ambiente da loja, indicativo de vedação ineficiente ou mal projetada. ${ }^{42}$ Até os anos 70 ainda havia muitos desses aparelhos em uso.

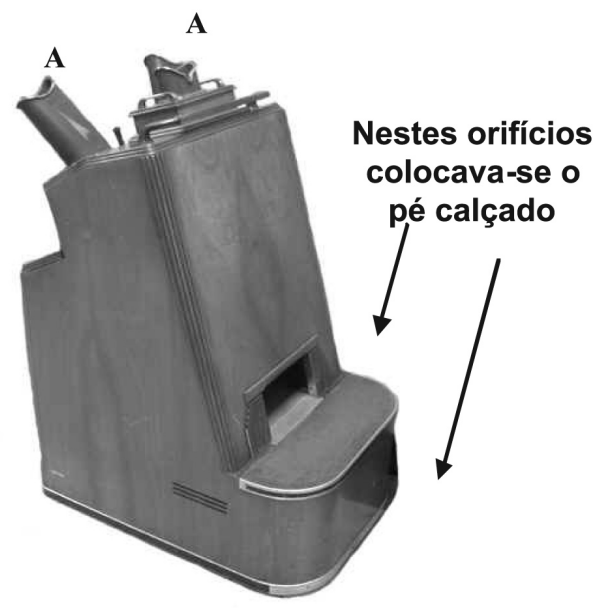

Figura 5. Modelo de fluoroscópio de sapataria, anos 30, origem norteamericana. Pela abertura na base, se colocavam os pés calçados; o aparelho continha dois visores fluorescentes. D.D.P.: $50.000 \mathrm{~V}$; tempo de exposição: 5 a 45 s. Reproduzido sob permissão de Oak Ridge Associated Universities, copyright (C) 1998. A = visor fluorescente

Além das citações em jornais e revistas os raios-x foram rapidamente incorporados à ficção científica do final do século XIX,${ }^{19}$ onde era destacada a capacidade dessa radiação de revelar objetos ocultos por corpos opacos, inclusive de pessoas. Assim objetos roubados ou escondidos eram revelados por essa técnica. Nas primeiras décadas do século XX, os raios-X continuaram a servir de fonte de inspiração para a imaginação de escritores e roteiristas, sendo apenas superados quando do advento da energia nuclear. ${ }^{20,33}$

Os raios-x também logo começaram a aparecer em obras literárias. No romance de Herbert George Wells (1866-1946), The Invisible Man (1897), o protagonista descobre um raio análogo aos "raios Roentgen", capaz de tornar seu corpo invisível, ${ }^{43}$ no romance de William S. Harris (1865-?), Life in a Thousand Worlds (1905), os cientistas, são capazes de "seguir o curso de um pensamento em um cérebro vivo depois de este ter sido tornado visível por uma luz mais potente que os raios-x". ${ }^{43} \mathrm{Na}$ obra de Thomas Mann (1875-1955, Prêmio Nobel de Literatura de 1929), The Magic Mountain (1924), um dos capítulos é denominado "Deus meu, eu vejo!". Nele, o autor descreve o encontro do personagem Hans Castrop, internado em um sanatório, com os raios-x. Defrontando-se pela primeira vez com as imagens de radiografias, Castorp não conseguiu entendê-las. Só depois que o médico do sanatório lhe sinalizou as diferentes partes anatômicas, Castorp exclamou: "Sim, sim, eu vejo (...). Deus meu, eu vejo!" ${ }^{21}$ Este romance mostra uma vivência comum nos indivíduos enfermos que tomaram contato com essa tecnologia no início do século XX: ao se relevarem detalhes internos de seus corpos, as pessoas se voltavam e refletiam sobre si mesmas, ao mesmo tempo em que o impacto subjetivo causado pelas imagens provocava reações de estranheza e insegurança quanto à vida e ao futuro. ${ }^{2,21,33}$ Para alguns, a experiência com radiografias era o prenúncio da morte futura: o esqueleto era o símbolo desse momento inevitável. ${ }^{2,33}$

Apesar da reação básica da sociedade ser de deslumbramento, na medida em que os raios-x eram tidos como uma diversão, ${ }^{2}$ algu- 
mas pessoas se revoltavam com aquele interesse desenfreado. $\mathrm{Na}$ verdade, elas sentiam-se ameaçadas com a idéia de que as imagens do interior de seus corpos pudessem tornar-se públicas, mesmo que anonimamente. Era consenso que as imagens eram privadas e íntimas, com valor sentimental, devendo ser zelosamente protegidas. ${ }^{21}$ A descoberta de Roentgen ocorreu em meio a uma sociedade conservadora. Uma tecnologia nova, capaz de revelar os segredos do corpo causava desconforto..$^{20,21,33,43}$ Os raios-x "ameaçavam expor" a parte mais oculta do corpo humano, os órgãos genitais. Uma firma de tecidos de Londres chegou a oferecer calcinhas à prova de raios- $\mathrm{X},{ }^{43}$ provavelmente de chumbo.

Outros indivíduos viam na nova tecnologia uma invasão da privacidade doméstica e da intimidade pessoal, temendo que os raios- $\mathrm{X}$ pudessem ver através dos muros de suas casas. ${ }^{10,33}$ A esse respeito, uma nota publicada no Pall Mall Gazette de Londres, em março de 1896 (4 meses depois da descoberta de Roentgen), descreve a atmosfera de insegurança e desconforto que os raios-x provocavam: ${ }^{21}$ "Estamos enojados com os raios Roentgen. Diz-se agora, esperamos que inveridicamente, que Mr. [Thomas] Edison descobriu uma substância - seu nome repulsivo é tungstato de cálcio - que potencializa (...) os ditos raios. A conseqüência disto parece ser que se pode ver os ossos das outras pessoas a olho nu, e também ver através de oito polegadas de madeira sólida. Não há necessidade de nos estendermos sobre a revoltante indecência disto. (...) Olhar os ossos de outra pessoa sem permissão deveria ser encarado como uma forma grave de atentado ao pudor. (...) Talvez a melhor coisa seria todas as nações civilizadas fazerem um pacto: queimar todos os trabalhos sobre os raios Roentgen, executar todos os descobridores, juntar (isolar) todo o tungstato do mundo, e afundá-lo no meio do Atlântico. Deixem os cetáceos, e não nós, contemplarem os ossos uns dos outros". ${ }^{20,21}$

Em 1902, em Nova Jérsei, Estados Unidos, deputados tentaram passar uma lei proibindo o uso da radiação x. Denominavam-se defensores da moralidade, e achavam que os raios-x permitiriam a qualquer um ver os corpos nus de quem andasse pelas ruas. ${ }^{2} \mathrm{~A}$ lei não foi aprovada, inclusive porque, no máximo, se veriam esqueletos.

Em meio a uma polêmica sobre a utilização da radiografia como prova material (dada a dificuldade de interpretação das imagens que não fosse feita por médicos ou operadores dos aparelhos), a primeira imagem de raios-X usada como evidência em tribunal ocorreu em fevereiro de 1896, em Montreal. Por volta de 1900, já sucediam casos de apresentação de imagens principalmente em processos por negligência médica. A partir dessa ocasião, ficou bem estabelecido o emprego de radiografias em processos no âmbito jurídico. ${ }^{43,44}$

\section{AS PRIMEIRAS APLICAÇÕES DOS RAIOS-X}

Cerca de 2 anos apenas após os trabalhos pioneiros de Roentgen, a primeira e imediata aplicação dos raios-x era a visualização das estrutura ósseas. Os raios-x permitiam a aplicação da fotografia para fins médicos e clínicos. A anatomia humana (e a de animais) jamais tinha sido investigada dessa forma, ainda mais com pessoas vivas, saudáveis ou não. As primeiras radiografias na área clínica foram feitas em um hospital de Birmingham (Inglaterra) em fevereiro de 1896. ${ }^{45}$ Ainda naquele ano hospitais já dispunham de departamentos de radiologia. ${ }^{20}$ As imagens de raios-x não eram reconhecíveis de modo imediato. A interpretação exigia treinamento do médico ou operador. ${ }^{21}$

Além do estudo dos ossos e dos cálculos (concreções que se formam em alguns órgãos internos), a localização de corpos estranhos introduzidos era outro feito assombroso, facilitando as cirurgias de retirada dos mesmos. O Brasil possui contribuições nesse campo. Álvaro Alvim (1863-1928) foi o primeiro a radiografar um caso de xipófagas (bebês nascidos unidos pelo corpo - bebês siameses), Rosalina e Maria, identificando os órgãos de cada uma delas, em 1897. A operação de separação foi conduzida com sucesso pelo cirurgião Eduardo Chapot Prévost (1864-1907), ganhando repercussão internacional. ${ }^{28,46}$ Outra contribuição brasileira ao diagnóstico com raios-x se deve a Manuel de Abreu (1892-1962), inventor da abreugrafia, permitindo o diagnóstico e tratamento da tuberculose pulmonar. ${ }^{47}$ Os primeiros resultados bemsucedidos foram obtidos em 1936, após duas tentativas frustradas. No ano seguinte, o primeiro aparelho diagnóstico de massa começou a operar no Rio de Janeiro. Ele foi premiado e homenageado no país e no exterior (hoje, restrições quanto à proteção radiológica limitaram o emprego da abreugrafia em muitos países). ${ }^{47}$

Além dessas indiscutíveis aplicações médicas, os médicos também logo perceberam o potencial daquela radiação para terapia, isto é, o tratamento de tumores malignos, e encontrar a solução de problemas que até então somente seria possível se o paciente fosse operado. ${ }^{45} \mathrm{De}$ modo geral, acreditava-se que os raios-x seriam uma nova e milagrosa arma da medicina contra inúmeras enfermidades. ${ }^{20}$

Muitas das aplicações testadas baseavam-se em práticas aplicadas na medicina eletroterapêutica (que usa o mesmo tipo de aparelhagem geradora). Em seu livro, editado apenas cerca de 7 meses após a primeira comunicação de Roentgen, ao preço de 25 centavos de dólar, Edward Trevert (1858-1904) ${ }^{34}$ sintetiza as aplicações (empíricas) dos raios-X ao final do século XIX, destacando-se a área medica: problemas de coração, impotência, úlceras, depressão, artrite, câncer, pressão alta, cegueira, tuberculose... e, também, a irradiação de tumores benignos (não cancerosos), que perdurou por mais de 40 anos. ${ }^{33}$ Até por volta de 1920, tinha-se a idéia de que cerca de 100 doenças respondiam favoravelmente ao tratamento com raios-X. ${ }^{33}$ Pessoas foram expostas à radiação para tratamento de acnes e coceiras. Mulheres tiveram seus ovários irradiados para combater a depressão pós-parto. Crianças eram colocadas dentro de fluoroscópios para prevenir o aparecimento de doenças, às vezes mensalmente e no check-up anual. Milhares de crianças tiveram seus cabelos removidos por radiação maciça apenas para tratamento de infecções do couro cabeludo.

Na seqüência, introduziu-se a técnica de contraste, que, pela ingestão de substâncias radiopacas, possibilitava a exploração de órgãos como o estômago, os rins, etc., que praticamente não absorviam a radiação. ${ }^{2}$ Para tal, emprega-se um agente de contraste, o sulfato de bário. Nas décadas de 10-20, alguns locais administravam sulfeto de bário, ao invés do sulfato, o que se revelou desastroso, porque o bário é um elemento extremamente tóxico ao ser humano, ${ }^{48}$ e podia haver liberação de $\mathrm{H}_{2} \mathrm{~S}$ no suco gástrico. Para evitar tal acidente, os fornecedores de $\mathrm{BaSO}_{4}$ para contraste passaram a fornecer este composto exclusivamente para esta finalidade. ${ }^{49} \mathrm{Na}$ década de 20 , o problema de manutenção do $\mathrm{BaSO}_{4}$ em suspensão aquosa foi resolvido (suspensão coloidal), antes havia a tendência de sedimentação, o que comprometia a qualidade da imagem e havia risco de constipação intestinal. ${ }^{50}$ Entre as décadas de 30 e 60, um outro tipo de contraste foi utilizado: o dióxido de tório coloidal (ca. $25 \%$ vol.), o qual produzia imagens mais nítidas e consistentes, ${ }^{51}$ e reduzia a chance de constipação intestinal. Este produto também foi empregado para contraste do sangue, ${ }^{51}$ o que levou ao aparecimento de cânceres em muitos dos milhões de seus usuários, 20-30 anos após tomarem o produto (o tório acumula-se no fígado e na medula óssea).

Fora da área médica, um dos usos mais relevantes dos raios-x é a análise de peças industriais (ensaio não-destrutivo) ${ }^{2}$ para a verificação de defeitos em artefatos metálicos e de borracha. ${ }^{52,53}$ Essa aplicação foi inicialmente notada por Roentgen: ao radiografar seu rifle de caça, observou uma pequena falha interna. Essa aplicação foi bastante empregada na I Guerra Mundial, no controle de qualidade de artefatos bélicos (canhões, obuses, etc.) ${ }^{27}$ As experiências pioneiras em que se radiografavam caixas de madeira fechadas com peças metálicas no interior (Figura 1) são hoje feitas em aeroportos, onde as bagagens são radiografadas pelo pessoal da segurança. 


\section{OS PERIGOS OCULTOS DOS RAIOS-X}

Desde praticamente a inserção dos raios-x no cotidiano, já havia quem reconhecesse o perigo real daquela radiação ainda mal conhecida, mas o fascínio que causava na grande maioria das pessoas fazia com que ignorassem os riscos da exposição sem cuidado. Ainda havia um diferencial importante: não havia nenhuma experiência prévia com aquela radiação, a ponto das queimaduras devidas a ela serem inicialmente descritas como de natureza "elétrica", face ao equipamento gerador também ser utilizado na medicina eletroterapêutica. ${ }^{3,54} \mathrm{~A}$ enorme curiosidade levou muita gente a correr sérios riscos de saúde em suas tentativas de novas aplicações dos raios-x. Em março de 1896, já havia um alerta para o público sobre o perigo desses raios para os olhos. ${ }^{55}$

Desde os primeiros tempos, muitos pesquisadores foram acometidos de úlceras, abscessos e graves queimaduras, que não cicatrizavam, levando a cirurgias desfigurantes, amputações ou mesmo à morte (câncer) ao trabalharem com raios-x sem a mínima proteção pessoal. ${ }^{10,12,28}$ Muitas das vítimas eram os operadores de fluoroscópios de rua, que sofriam exposições repetidas. Vários perderam as mãos. ${ }^{31}$ Operadores de fluoroscópios de sapatarias desenvolveram dermatites e queimaduras de pele pela exposição repetida aos raios-x durante anos. ${ }^{42}$ Os usuários que faziam tratamento de branqueamento da pele e de remoção de cabelos indesejados eram outras vítimas comuns. ${ }^{56}$

Os aparelhos de raios-X do final do século XIX e início do XX emitiam enormes doses de radiação e sem controle. Álvaro Alvim morreu acometido de grave radiodermite, que levou à amputação de suas mãos e antebraço. ${ }^{28}$ Mihran Kassabian (1870-1910) documentou fotograficamente as horríveis amputações que sofreu. Ele desejava com isso que nenhum operador ou paciente sofresse o que ele estava passando. ${ }^{2}$ Naquela mesma ocasião vieram os primeiros relatos da necessidade de algum tipo de radioproteção. Francis Williams (1852-1936), Chester L. Leonard (1861-1913) e Emil Grubbe (1875-1960) sugeriam, dentre outras medidas, o uso de couro e de chumbo como elementos protetores do tubo de radiação e do paciente..$^{18,57}$ Mesmo assim o verdadeiro risco da radiação continuou sendo essencialmente ignorado.

As aplicações médicas eram basicamente realizadas sem o conhecimento dos efeitos biológicos da radiação (os primeiros estudos sobre os efeitos desta na genética somente foram publicados em 1927), significando a execução dos exames e de outras práticas sem qualquer tipo de proteção para o paciente (ou voluntário) e o operador do equipamento.

$\mathrm{O}$ que também alguns médicos afirmavam ${ }^{55}$ é que eram necessários testes científicos e não comerciais para que o real papel dos raios-x na terapia dos cânceres e outras doenças fosse compreendido, e "o que se viu até agora em termos de aplicação dos raios desse tal de Sr. Roentgen é a eliminação temporária dos efeitos dos carcinomas, sujeitos a recidiva, metátase e difusão pelo sistema [o corpo]. $O$ desconhecido tem um efeito fascinante para os cidadãos comuns, até mesmo às vezes para os lógicos, mas para os que têm consciência da verdade, quase nada - exceto os perigos". O impacto das manchetes relativas à cura de doenças eram das mais apreciadas pelas pessoas, sem que houvesse preocupação com a real seriedade das pesquisas e dos pesquisadores responsáveis. ${ }^{59}$

Os casos de morte ou invalidez nos primeiros anos do emprego dos raios-x eram os únicos a causar impacto nas pessoas, mas eram considerados como apenas devidos a acidentes. ${ }^{58}$

\section{A NECESSIDADE DE UMA PROTEÇÃO RADIOLÓGICA}

Com o passar dos anos, os relatos que se acumulavam alertavam sobre o fato de que as consequiências biológicas da radiação $\mathrm{x}$ poderiam se tornar nocivas dependendo de como essa radiação era utilizada.
Em 1902 parece que foi feita a primeira tentativa de se estabelecer um nível limite de exposição, muito embora a pouca compreensão daquela radiação dificultasse o estabelecimento de algo fidedigno. ${ }^{60}$ Em 1915 a British Roentgen Society (fundada em 1897) adotou uma resolução sobre a proteção no uso dos raios-x. Cinco anos depois a American Roentgen Ray Society (fundada em 1900) estabeleceu uma comissão para determinar medidas de proteção radiológica ${ }^{60}$ No ano seguinte, a British X-ray and Radium Protection Committe apresentou suas primeiras regras de proteção radiológica, culminando em 1925 com a proposta de um limite de exposição para a pele.

Apesar dessas propostas e tentativas, não havia um método uniforme de medida de radioatividade e de controle da radiação emitida pelos aparelhos de raios- $\mathrm{x}$ aos quais os operadores estavam expostos. Havia, até a idéia de se "medir" a radiação avaliando o tempo necessário para que a pele (de uma mão, por exemplo) ficasse avermelhada sob os raios- $\mathrm{x} !^{8}$ Assim, era difícil comparar os resultados de pesquisas de um país em outro e até mesmo determinar a radiação sem um padrão de referência. Ao final da I Guerra Mundial operadores e médicos estavam temerosos de continuarem a trabalhar com os raios-x, dado o nível de exposição elevado e os casos de deterioração da saúde e mesmo a morte em seus colegas. ${ }^{60,61} \mathrm{O}$ desejo era que se estabelecesse um nível de exposição-limite à radiação pelo ser humano em condições razoáveis de confiabilidade e de segurança. Só que com o quadro no início dos anos 20, isso não era possível.

Essa situação motivou a realização do primeiro congresso mundial de radiologia, em Londres em 1925, tendo como um de seus principais feitos a criação de uma comissão para elaborar uma proposta de medida e de uma unidade para a radiação, de aceitação internacional. Sem isso se acreditava que não se chegaria a um progresso na área de radioproteção. Nesse mesmo ano foi fundada a Sociedade Internacional de Radiologia, que não tinha conexão com os dois primeiros congressos de radiologia realizados (ela os assumiu na década de 50). Em 1928 ocorreu o segundo congresso, em Estocolmo, com o estabelecimento da ICRP (International Comission on Radiological Protection) e do ICRU (International Committee on Radiation Units and Measurements). Logo a seguir foi adotado o Roentgen como unidade de exposição radioativa, equivalente a uma desintegração por segundo. Logo após a realização do $2^{\circ}$ Congresso Mundial de Radiologia, foi fundada em 1929, no Rio de Janeiro, a Sociedade Brasileira de Radiologia, cujos membros tiveram o grande mérito de trabalhar pela aprovação da Lei 1234, que trata dos perigos do trabalho com radiação. ${ }^{28}$

Em 1934, o ICRP propôs uma dose diária tolerável de radiação que, 2 anos depois, foi fixada em 0,1 R por dia. Em 1956, a radiação em higiene ocupacional foi limitada a 5 R por ano. Somente em 1975 o SI adotou as unidades relacionadas à radiação e à radioatividade (Tabela 2). ${ }^{8,18}$

É preciso esclarecer que todos nós estamos envolvidos por radiação, ela é parte integrante do meio ambiente. Diferentes tipos de radiação nos tocam a cada instante: raios infravermelhos, radiação ultravioleta, visível, raios cósmicos... Pela Tabela 3, observa-se que cerca de $82 \%$ da energia de origem radiativa provém de origem natural (radônio, raios cósmicos, rochas terrestres contendo elementos como $\mathrm{U}$ e Th, radioisótopos naturais presentes nos seres vivos como $\mathrm{C}^{14} \mathrm{e}$ $\mathrm{K}^{40}$ ), enquanto que $18 \%$ é de origem antropogênica (especialmente devido aos raios-x) ${ }^{58} \mathrm{O}$ problema é a exposição a fortes doses de radiação (às vezes, repetidas) em tempo relativamente curto e sem as medidas de controle necessárias.

\section{CONCLUSÕES}

A descoberta dos raios-x representou um dos grandes feitos da inteligência humana no final do século XIX, tendo uma repercussão 
Tabela 2. Unidades de medida de radiação

\begin{tabular}{|c|c|c|c|c|}
\hline Grandeza radiológica & Expressão matemática & Unidade atual & Unidade antiga & Definição \\
\hline $\begin{array}{l}\text { Atividade }(A) \\
\text { unidade mais utilizada } \\
\text { para determinação } \\
\text { de radioatividade }\end{array}$ & $A=\frac{d N}{d t}$ & Becquerel (Bq) & $\begin{array}{c}\text { Curie }(\mathrm{Ci}) \\
1 \mathrm{Ci}=3,7 \times 10^{10} \\
\mathrm{~Bq}\end{array}$ & $\begin{array}{l}\text { Corresponde a uma trans- } \\
\text { formação por segundo. }\end{array}$ \\
\hline Exposição $(X)$ & $X=\frac{d Q}{d m}$ & $\begin{array}{c}\text { Roentgen }(\mathrm{R}) \\
1 \mathrm{R}=2,58 \times 10^{-4} \\
C \mathrm{~kg}^{-1}\end{array}$ & & $\begin{array}{l}\text { Valor absoluto de todos os } \\
\text { elétrons liberados pelos } \\
\text { fótons no ar em uma massa } \\
d m \text { que são freados comple- } \\
\text { tamente no ar. }\end{array}$ \\
\hline Dose absorvida $(D)$ & $D=\frac{d \varepsilon}{d m}$ & $\begin{array}{l}\text { Gray (Gy) } \\
\left(J k^{-1}\right)\end{array}$ & $\begin{array}{c}\operatorname{rad} \\
100 \mathrm{rad}=1 G y\end{array}$ & $\begin{array}{c}\text { Relaciona a energia absor- } \\
\text { vida e a massa do volume } \\
\text { de material atingido. }\end{array}$ \\
\hline Equivalente de dose $(\mathrm{H})$ & $H=D \cdot Q$ & $\begin{array}{l}\text { Sievert (Sv) } \\
\quad\left(J k g^{-1}\right)\end{array}$ & & $\begin{array}{l}\text { Relaciona a dose absorvida } \\
(D) \text { com o tipo de radiação } \\
\text { (fornecido pelo fator de } \\
\text { qualidade efetivo } Q \text { ) }\end{array}$ \\
\hline
\end{tabular}

Tabela 3. Estimativa da origem de toda a radiação ionizante incidente sobre o ser humano*

\begin{tabular}{lcc}
\hline Fonte & Tipo & Percentual \\
\hline Natural & Radônio & 55 \\
& Raios cósmicos & 8 \\
& Rochas terrestres & 8 \\
& Radioisótopos & 11 \\
& $\left(\mathrm{C}^{14}, \mathrm{~K}^{40}\right.$, etc. $)$ & 11 \\
Artificial (antropogênica) & Raios-x (medicina) & 4 \\
& Medicina nuclear & 3 \\
& Produtos de consumo & Outros (doenças \\
& ocupacionais, acidentes) & $<1$ \\
\hline
\end{tabular}

* adaptada da ref. 58

imediata em todo o mundo. Em paralelo aos esforços de interpretação da radiação $\mathrm{x}$, muitas especulações foram feitas, vindo a causar um grande interesse e fascínio nos cientistas e nos cidadãos comuns. Embora a reação em geral tenha sido de deslumbramento com aquela nova radiação, outras posturas foram observadas, mostrando uma relação de repulsa ou de medo/insegurança pessoais.

As propriedades dos raios- $\mathrm{x}$, quer tenham encantado ou desagradado as pessoas, ocultavam os perigos advindos de sua manipulação indevida. Foi preciso um acúmulo de erros e tragédias para que se despertasse nas pessoas a necessidade do estabelecimento de protocolos de proteção radiológica, bem como da supressão de muitas das aplicações empíricas no cotidiano que eram feitas no início do século XX.

\section{MATERIAL SUPLEMENTAR}

O material suplementar, disponível gratuitamente em http:// quimicanova.sbq.org.br na forma de arquivo PDF, apresenta as duas reportagens publicadas em fevereiro de 1896 , em jornais do Rio de Janeiro, sobre a descoberta dos raios-x.

\section{REFERÊNCIAS E NOTAS}

1. Glasser, O.; William Conrad Roentgen and the Early Story of the Roentgen Rays, Charcles C. Thomas: Springflied, 1934.

2. http://www.orau.org/ptp/collection/quackures/radsup.htm, acessada em
Fevereiro 2007; http://www.if.ufrgs.br/tex/fis142/raiosx/rxhist.html, acessada em Agosto 2007.

3. http://www.xray.hmc.psu.edu, acessada em Dezembro 2007.

4. Patton, D.; Invest. Radiol. 1993, 28, 954.

5. Roentgen, W. C.; Annalen der Physik und Chemie 1895, 64, 1.

6. Roentgen, W. C.; Rev. Gen. Sci. 1896, 7, 59.

7. Martins, R. A.; Rev. Bras. Ens. Fis. 1998, 20, 373; Martins, R. A.; Cienc. \&. Educ. 2004, 10, 501.

8. Linton, O. W.; palestra de abertura do $23^{\text {th }}$ International Congresso on Radiology, Montreal, 25 de junho de 2004.

9. Kravetz, R. E. ; Am. J. Gastroenterology 2001, 96, 1273.

10. Jauncey, G. E. M.; Am. J. Phys. 1945, 13, 362.

11. Poincaré, H.; Rév. Sci. 1897, 4, 72.

12. Martins, R. A.; Revista da SBHC 1997, 17, 81.

13. http://nobelprize.org/nobel_prizes/physics/laureates, acessada em Setembro 2007

14. Keller, C.; Radioquímica, $2^{\mathrm{a}}$ ed., Ed. Universitária UFPE: Recife, 1981.

15. Moreau, G.; Comp. Rend. Acad. Sci. Paris 1896, 122, 238.

16. Benoist, L.; Hurmuzescu, D.; Comp. Rend. Acad. Sci. Paris 1896, 122, 235.

17. Martins, R. A.; Cad. Cat. Ens. Fis. 1990, 7, 27.

18. Tauhata, L.; Salati, I. P. A.; Di Prinzio, R; Di Prinzio, A. R.; Radioproteção e dosimetria: Fundamentos, $5^{\text {a }}$ revisão, IRD/CNEN: Rio de Janeiro, 2003.

19. Foulger, S.; Phys. Rev. 1996, 5, 330.

20. Hessenbruch, A.; Endeavour 2002, 26, 137.

21. Ortega, F.; História, Ciências e Saúde - Manguinhos, Rio de Janeiro 2006, vol. 13, 89; Keller, C.; The Naked Truth or the Shadow of Doubt? $X$-rays and the Problematic of Transparency, http://www.rochester.edu/ in_visible_culture/Issue_7/Issue_7_Keller.pdf, acessada em Março 2008.

22. Jornal O Paiz, 14 de fevereiro de 1896.

23. Jornal do Commercio do Rio de Janeiro, 16 de fevereiro de 1896.

24. Williams, F. H.; Rollins, W. H.; J. Am. College of Radiology 2006, 3, 478.

25. Daniel, J.; Science 1896, 3, 562.

26. Notas sobre os raios de Roentgen e sua Introdução no Brasil - arquivos do Prof. Henrique Morize, Museu de Astronomia e Ciências Afins (MAST) - http://www.mast.br.

27. Couto, N. F.; Ribeiro, R. S.; Azevedo, A. C. P.; Carvalho, A. C. P.; Radiologia Brasileira 2003, 36, 14.

28. Carvalho, A. C. P.; Ver. Imagem 2001, 23, 283; Ribeiro, L.; Pelos 
Caminhos da Medicina, Editora Vete: Rio de Janeiro, 1976.

29. Frey, J. E.; J. Chem. Educ. 1966, 43, 371; Jensen, W. P.; Palenik, G. J.; Suh, I. H.; J. Chem. Educ. 2003, 80, 753.

30. The New York Journal, 20 de dezembro de 1896.

31. The New York Times, 11 de janeiro de 1901.

32. Revista Life, 27 de fevereiro de 1896, capa.

33. Caufield, C.; Multiple Exposures: Chronicles of the Radiation Age, Harper \& Row: Nova Iorque, 1989; Kemp, M. Em Beauty of Another Order Photography in Science; Thomas, A., ed.; Yale University Press: Londres, 1998, p. 120-149.

34. Trevert, E.; Something About X-rays for Everybody, Bubier Publishing: Lynn, 1896.

35. Magnes, C. I.; Isis 1956, 47, 236.

36. The New York Times, 20 de novembro de 1903.

37. Anúncio publicado no Jornal The New York Times, $1^{\circ}$ de fevereiro de 1921.

38. The New York Times, 15 de março de 1896.

39. Duffin, J.; Hayter, C. R. R.; Isis 2000, 91, 260.

40. The London Times, 31 de dezembro de 1925.

41. Lowe, J. J.; American Patent 1,614,988, 1927; Bavley, H.; National Safety News 1950, 62, 107.

42. Fredrick, W. G.; Smith, R. G.; Am. Ind. Hyg. Quart. 1948, 9, 89; Williams, C. R.; New Eng. J. Med., setembro de 1949, p. 333-335; Hempelmann, L. H.; New Eng. J. Med., setembro de 1949, p. 335-336.

43. Kelves, B. H.; No Kid to the Bone: Medical Imaging in the Twentieth Century, Hellis Boots: Reading (Massachutess), 2006, p. 520.
44. Reiser, S. J.; Medicine and the Reign of Technology, Cambridge University Press: Cambridge, 1990.

45. Brecher, R.; Brecher, E.; The X-rays: a History of Radiology in the United States and Canada, Williams and Wilkins: Baltimore, 1969.

46. Kroeff, M.; Resenha da Luta Contra o Câncer no Brasil, Serviço Nacional de Câncer: Rio de Janeiro, 1946.

47. Bedrikow, R.; J. Pneumologia 2001, 27, 52.

48. Tubino, M.; Simoni, J. A.; Quim. Nova 2007, 30, 505.

49. http://www.orau.org/ptp/museumdirectory.htm, acessada em Setembro 2007.

50. Patton, D.; Invest. Radiology 1994, 29, 472.

51. Abbatt, J. J.; Environ. Res. 1979, 18, 6.

52. Clarck, L. C.; J. Chem. Educ. 1931, 8, 625.

53. Hershey, R. L.; J. Chem. Educ. 1927, 4, 1335.

54. The New York Journal, 12 de abril de 1903.

55. The St. Louis Globe-Democrat Journal, 29 de março de 1896.

56. The New York Times, $1^{\circ}$ de julho de 1928.

57. McCourt, M. D.; Medical Review of Reviews, abril 1904, p. 23.

58. http://www.Physics.isu.edu/radinf/1stpart1-2.htm, acessada em Janeiro 2008.

59. Hering, D. W.; Foibles and Fallacies of Science, Van Nostrand: Nova Iorque, 1924.

60. http://www.physics.isu.edu/radinf/1stpart1-2.htm, acessada em Fevereiro 2008.

61. Tarbell, D. S.; Tarbell, A. T.; Hamilton, J. H.; J. Chem. Educ. 1981, 58, 275 . 


\section{RAIOS-X: FASCINAÇÁO, MEDO E CIÊNCIA}

Rodrigo da Silva Lima e Júlio Carlos Afonso*

Departamento de Química Analítica, Instituto de Química, Universidade Federal do Rio de Janeiro, Av. Athos da Silveira Ramos, 149, 21941-909 Rio de Janeiro - RJ, Brasil

Luiz Cláudio Ferreira Pimentel

Instituto de Radioproteção e Dosimetria, Comissão Nacional de Energia Nuclear, Av. Salvador Allende, s/n, 22780-160 Rio de Janeiro - RJ, Brasil

\section{Maravilhas do Século (Jornal o Paiz, edição de $4^{a}$ feira, 14 de fevereiro de 1896)}

"Estupenda descoberta preocupa actualmente o mundo scientifico europeu e já della tivemos ha dias telegrammas, cuja linguagem consisa nada explicava. Chegam-nos agora revistas scientificas e jornaes medicos, que vieram esclarecer melhor a estupenda descoberta annunciada.

Há pouco era o mundo scientifico abalado com a descoberta perfeitamente verificada por Lord Rayleigh e Ramsay da existencia do argon [argônio], um novo elemento até então totalmente desconhecido na atmosphera. (...) Isto é entretanto mui pouco diante da propriedade maravilhosa, mágica, que tem a nova luz de poder atravessar corpos opacos, como o papelão, a madeira, metaes, etc, etc. Graças a nova luz pode se photographar corpos e peças resguardadas por substâncias chamadas opacas.

É obtida fazendo-se passa uma corrente eléctrica no vacuo. Seu descobridor foi o professor Dr. Roentgen, da Universidade de Wurtzburgo. Nas sociedades medicas de Berlim e de Paris têm sido apresentadas photographias de mãos e de outras partes do corpo humano em que as partes internas, ossos, articulações e ligamentos acham-se fielmente representados, a despeito da capacidade dos tecidos molles que não constituem obstaculo a nova luz. (...)

Já a medicina aproveitando a grande descoberta, procurou della auferir todas as vantagens possiveis. E quaes possam ellas ser, tornarse intuitiva diante do poder que possui a nova luz, cujos raios indo ao âmago do corpo humano conseguirão revelar com precisão admirável tanta coisa que ao medico até hoje tem sido possível conhecer pelo exame subjetivo e por meio de inducções mais ou menos fundadas.

Já antes de hontem a bem informada Notícia publicou um telegramma de Berlim, tornando conhecido o primeiro ensaio da nova descoberta applicada a medicina, coroado de resultado. Que surpresas nos reserva ainda esse fim de século?!"

\section{A Photographia Atravez dos Corpos Opacos (Jornal do Commercio do Rio de Janeiro, edição de $6^{a}$ feira, 16 de fevereiro de 1896)}

"O eminente professor de physica Wilhelm Conrad Roentgen, de Wutzburgo, acaba de fazer uma descoberta destinada, se os seus resultados se confirmarem amplamente, a produzir uma profunda revolução nas sciencias, sobretudo na medicina e mais particularmente e immediatamente ainda na cirurgia. Trata-se de uma descoberta realmente assombrosa, a photographia atravez dos corpos opacos, impenetraveis à luz (...). A descoberta delles é sem dúvida uma das maiores conquistas da sciencia, predestinada a levantar uma ponta do véo de tantas cousas occultas até hoje aos nossos olhos, e cuja applicação irá determinar os mais inesperados resultados. Limitamo-nos por hoje a apresentar aos leitores as experiencias que se tem feito em tal sentido e que, como se verá, têm sido as mais satisfatorias.

O Dr. Spiess, de Berlim, offereceu as seguintes provas do grande valor da descoberta. Poz num porte monnaie uma chave e algumas moedas, embrulhou o volume em papel preto, collocou-o diante de uma chapa photographica e, entre estes objetos e a luz electrica, uma taboa de madeira da grossura de dous dedos. Em quinze minutos sahio uma photographia na qual se vião com perfeita nitidez a chave, as moedas e um contorno muito ligeiro do porte monnaie. A taboa não appareceu na photographia. Identico resultado para uma corrente de relogio mettida em uma caixa de madeira. (...) O Dr. Spiess photographou ainda a mão de um operario vidraceiro, que continha havia muitos annos um estilhaço de vidro. A photographia revelou o ponto exacto do corpo extranho.

O jornal de medicina inglez Lancet refere à seguinte observação relativa a um doente, que se achava em tratamento havia muitos mezes em um dos grandes hospitaes, o Guy's hospital. Este individuo, que era marinheiro, tinha sido encontrado ébrio moribundo em um distrito mal afamado de Londres e transportado para o hospital. Passada a embriaguez, verificou-se que o infeliz estava paralytico das extremidades superiores e inferiores. $\mathrm{O}$ exame mais minucioso não revelou mais do que insignificante chaga, situada na região dorso-lombar, e que não tardou a cicatrizar-se no fim de poucos dias. Desde então e a despeito de toda a medicação, o doente se conservava paralytico, quando o Dr. Williamson, chefe do serviço, teve a idéia de photographar a parte da columna vertebral correspondente à ferida. $\mathrm{O}$ cliché revelou-lhe a presença de um corpo extranho, cuja natureza não pode elle logo determinar, visto que estava insinuado entre a primeira vertebra dorsal e a primeira vertebra lombar. Uma incisão no ponto preciso correspondente fez-lhe descobrir uma lamina de faca tão fortemente incrustada nos corpos vertebrais que lhe foi preciso empregar reaes esforços para extrahi-la. No fim de poucos dias o doente teve alta.

(...) Como se vê, as applicações praticas já são numerosas, tendo produzido os melhores resultados. Acompanharemos com o maior interesse todas as pesquisas e aperfeiçoamentos que se fizerem, e no escriptório de nossa folha temos à disposição dos leitores uma admirável photographia de uma mão humana, na qual se pode perfeitamente estudar a anatomia". 